\title{
Ergenlerde Duygusal İstismar, Problem Davranışlar, Öz- Yeterlik ve Psikolojik Sağlamlık Arasındaki İlişki
}

\begin{abstract}
Gökmen ARSLAN*
Murat BALKIS ${ }^{* *}$

Öz

$\mathrm{Bu}$ çalışmanın amacı ergenlikte anne-babadan algılanan duygusal istismar ile problem davranışlar arasındaki ilişkide öz-yeterlik ve psikolojik sağlamlığın aracı rolünü incelemektir. Ölçme araçları Isparta il merkezinde farklı ortaöğretim kurumlarına devam eden 331 öğrenciye uygulanmıştır. Öğrencilerin \%55.6'sı (184) kız, \%44.1'i (146) erkek katılımcılardan oluşmaktadır. Öğrencilerin yaşları 14 ile 19 arasında değişmektedir. Yaş ortalaması 15.43'tür. Analiz sonuçları, anne-babadan algılanan duygusal istismarın psikolojik sağlamlık, öz-yeterlik ve problem davranışlarını doğrudan yordadığını göstermiştir. Ayrıca analiz sonuçları incelendiğinde, anne-babadan algılanan duygusal istismar ile problem davranışlar arasındaki ilişkide öz-yeterlik ve psikolojik sağlamlığın kısmi aracılık rolü üstlendiği görülmüştür. Son olarak anne-babadan algılanan duygusal istismar ve psikolojik sağlamlık arasındaki ilişkide öz-yeterliğin kısmi aracılık rolü üstlendiği bulunmuştur. Ergenlerde anne-babadan algılanan duygusal istismar ve problem davranışlar arasındaki ilişkide psikolojik sağlamlık ve öz-yeterliğin koruyucu faktörler olduğu, alan yazınla ilişkisi çerçevesinde tartışılmış ve bazı önerilerde bulunulmuştur.
\end{abstract}

Anahtar Kelimeler: Duygusal İstismar, Öz-Yeterlik, Psikolojik Sağlamlık, Problem Davranışlar, Ergenlik

\section{The Relationship Between Emotional Maltreatment,}

\section{Problem Behaviors, Psychological Resilience, and Self- Efficacy in Adolescents}

\begin{abstract}
The purpose of this study is to investigate the mediating role of psychological resilience and selfefficacy in relationship between emotional maltreatment and problem behaviors in adolescents. The measures were applied 331 students studying different high school in Isparta. Participants consisted of $55.6 \%$ (184) female, $44.1 \%$ (146) male students. The ages of the students ranged between 14 and 19. The mean of ages were 15.43. Results of analysis indicated that emotional malt-
\end{abstract}

\footnotetext{
* Dr., Süleyman Demirel Üniversitesi, Eğitim Fakültesi, Rehberlik ve Psikolojik. Danışmanlık Bölümü, gkmnarslan@gmail.com

** Doç. Dr., Pamukkale Üniversitesi Eğitim Fakültesi, Rehberlik ve Psikolojik. Danışmanlık Bölümü, mbalkis@pau.edu.tr
} 
reatment perceived parents directly predicted psychological resilience, self-efficacy and problem behaviors. Results also showed that emotional maltreatment perceived from parents indirectly predicted problem behaviors via self-efficacy and psychological resilience. In other words, psychological resilience and self-efficacy had partial mediation role in relationship between emotional maltreatment and problem behaviors in adolescents. Finally, it was found that self-efficacy partially mediate in the relationship between emotional maltreatment and psychological resilience. These results are discussed as suggestive of the role of self-efficacy and psychological resilience as protective factors in the link between emotional maltreatment and problem behaviors.

Keywords: Emotional maltreatment, Self-Efficacy, Psychological Resilience, Problem Behaviors, Adolescence.

\section{Gíriş}

Günümüzde duygusal istismar önemli psikososyal problemlerden biri olarak görülmektedir. Ülkemizde yaklaşık iki çocuktan biri duygusal istismara maruz kalmaktadır (Korkmazlar-Oral, Engin ve Büyükyazıcı, 2010). Duygusal istismar, çocuğa bakım veren kişilerin süreklik gösteren ve çocuğa karşı psikolojik açıdan yıkıcı etkilere sahip davranışlar sergilemesi olarak tanımlanır (Diagnostic and Statistical Manual of Mental Disorders [DSM-V], 2013; World Health Organization [WHO], 1999). Duygusal istismar; çocuğun gelişimsel sürecini sekteye uğratan, duygusal ve davranışsal problemleri tetikleyen, çocuğun iyilik halini ortadan kaldıran davranışları içerisinde barındırır (Iwaniec, 2006). Bu nedenle duygusal istismarın olduğu ortamda büyüyen bireylerin, diğerlerine göre daha fazla içe yönelim ve dışa yönelim problemleri yaşadıkları belirtilmektedir (Bolger ve Patterson, 2003; Iwaniec, 2006; Vranceanu, Hobfoll ve Johnson, 2007). Sonuç olarak duygusal istismarın bireyin iyi oluşu ve ruh sağlığı ile yakından ilişkili olduğu söylenebilir.

Yapılan çalışmalarda, istismara maruz kalma ile problem davranışlar arasında pozitif yönde bir ilişkinin olduğu rapor edilmiştir (Arslan ve Balk1s, 2014; Holden ve Ritchie, 1991; Ireland ve diğerleri, 2002; Kabasakal ve Arslan, 2014; Taşdelen, 1995). McGee, Wolfe ve Wilson (1997) duygusal istismara uğrayan bireylerin istismar yaşantısı olmayanlara göre daha fazla problem davranışlara yöneldiklerini belirtmiş- lerdir. Evans ve Burton (2013) tarafından duygusal istismarın suça karışma üzerinde önemli bir faktör olduğu bulunmuştur. Arslan (2012) tarafından aile içerisinde istismar algısı arttıkça ergenlerde alkol kullanımı, sigara kullanımı, anti-sosyal davranışlar, intihar eğiliminin arttığ1 ve beslenme alışkanlıklarının bozulduğu rapor edilmiştir. Duygusal istismara maruz kalan bireylerin daha fazla problem davranışlara yöneldikleri görülmektedir (Iwaniec, Larkin ve McSherry, 2007). Fakat birtakım özellikler bireyleri olumsuz yaşantılar karşısında daha güçlü kılar (Benetti ve Kambouropoulos, 2006; Çataloğlu, 2011). Bu özellikler genellikle psikolojik sağlamlık kavramı altında değerlendirilmektedir. Dolayısıyla psikolojik sağlamlık düzeyi yüksek olan ergenlerin daha az problem davranışlara yöneldikleri ileri sürülebilir.

Bireyin karşılaşmış olduğu olumsuz yaşantılara rağmen sağlıklı şekilde gelişim göstermesi genellikle psikolojik sağlamlık olarak ele alınır (Sameroff, 2005). Stewart, Reid ve Mangham (1997) tarafından psikolojik sağlamlık; önemli değişim, olumsuzluk veya risklerle karşılaşıldığında bireyin başarılı bir şekilde bunlarla başa çıkabilme yeterliği veya kapasitesi olarak tanımlanmıştır. Psikolojik sağlamlığa ilişkin farklı tanımlar olmasına rağmen alan yazında birtakım ortak kavramlar üzerinde odaklanıldığ1 söylenebilir. Tanımlarda olumsuz yaşam olayların kapsayan veya tetikleyen risk faktörleri, risk faktörlerinin etkisini hafifleten/azaltan veya engelleyen, sağlıklı uyumu ve bireyin yeterliklerini geliştiren koruyucu faktörler ve 
sürecin sonunda ortaya çıkan uyum sıklıkla değinilen kavramlar olarak karşımıza çıkmaktadır (Gizir, 2007; Windle, 2002). Bu nedenle psikolojik sağlamlık sürecinde koruyucu ve risk faktörleri arasındaki etkileşimin etkisinin oldukça fazla olduğu söylenebilir (Windle, 2002). Yapılan çalışmalarda duygusal istismar ile psikolojik sağlamlık arasında negatif bir ilişkinin olduğu rapor edilmiştir (Hussain ve Munaf, 2012; Cicchetti, 2013). Arslan ve Kabasakal (2014a) ergenlik döneminde annebabadan algılanan duygusal istismar arttıkça psikolojik sağlamlığın düştüğü bulunmuştur. Ayrıca bu çalışmada anne-babadan algılanan duygusal istismar ile uyum sorunları arasındaki ilişkide psikolojik sağlamlığın koruyucu rolü olduğu belirtilmiştir.

Araştırmacılar, psikolojik sağlamlık düzeyi yüksek bireylerin problem davranışlara daha az yöneldikleri üzerinde durmuşlardır (Kabasakal ve Arslan, 2014; Masten, 2001). Olumsuz yaşantılar karşısında bireyin psikolojik sağlamlığının düşük olması, birtakım uyum sorunlarina neden olabilmektedir (Fergusson ve Horwood, 2003). Leea ve Cranford (2008) problemli alkol sorunu olan ebeveyne sahip ergenlerde, alkol kullanan ebeveyne sahip olma ile içsel ve dışsal uyum sorunları arasındaki ilişkide psikolojik sağlamlığın farklılaştırıcı rolünün incelemek için yapılan çalışmada, psikolojik sağlamlık düzeyi düşük olan bireylerin daha fazla uyum sorunları yaşadıkları, problem davranışlara yöneldikleri rapor etmiştir. Kim ve Im (2014) psikolojik sağlamlık ile içsel ve dışsal uyum sorunları arasında negatif bir ilişkinin olduğu belirtilmiştir. Bu bağlamda koruyucu bir faktör olarak psikolojik sağlamlığın desteklenmesinin ergenler için problem davranışlara karşı koruyucu rol üstlenebilir (Rew ve Horner, 2003).

Ergenlikte anne-babadan algilanan duygusal istismar karşısında problem davranışlar üze- rinde koruyucu olabilecek diğer bir faktörde öz-yeterliktir. Öz-yeterlik, bireyin başarıya ulaşmak için becerilerine ilişkin inançları olarak tanımlanır (Bandura, 1997). Ebeveyn ve çocuk arasındaki ilişki, öz-yeterliğin gelişiminde önemli yer edinir. Duygusal istismara maruz kalan bireylerin öz-yeterlik düzeylerinin daha düşük olduğu belirtilmektedir (Hussain ve Munaf, 2012; Iwaniec, 2006). Yates (2007) yaptığ1 çalışmada duygusal istismar yaşantısı olan bireylerin öz-yeterlik düzeylerinin daha düşük olduğunu bulmuştur. Kim ve Cicchetti (2003) tarafından yapılan bir çalışmada istismar ve ihmal yaşantısı olan ergenlerin olmayanlara göre öz-yeterlik düzeylerinin daha düşük olduğu bulunmuştur. Ayrıca öz-yeterliğin bireyin davranışları üzerinde belirleyici rol oynadığ1 belirtilmektedir (Telef ve Karaca, 2011). Öz-yeterlik duygu, düşünce ve davranışları üzerindeki etkisiyle, ergeni problem davranışlara karşı koruyabilmektedir. Ergenlik dönemiyle birlikte birey, karşılaşmış oldukları zorluluklar ile nasıl başa çıkacağını öğrenir. Bu nedenle öz-yeterlik duygusunun güçlü olması ergenlerin problem davranışlarla baş etmelerinde önemli yer edinir (Bandura, 1994). Bandura, Pastorelli, Barbaranelli ve Caprara (1999) tarafından akademik öz-yeterliğin problem davranışları anlamlı düzeyde yordadığını ve problem davranışlar üzerinde önemli rol oynadığ1 belirtilmiştir. Ayrıca öz-yeterlik inancı, olumsuz bir yaşantı ile karşılaştığında, bireyin normlar çerçevesinde davranışlarını düzenlemesine yardımcı olur (Caprara, Barbaranelli, Pastorelli ve Cervone, 2004). Olumsuz yaşam olayları veya risk durumları karşısında, bireyin yüksek öz-yeterlik duygusuna sahip olması, bu yaşantıları nasıl yöneteceği belirlemekte ve problem davranışlara karşı bireyi korumaktadır (Telef ve Karaca, 2011). Uysal ve YılmazBingöl (2014) problem davranışlar ile özyeterlik arasında negatif bir ilişkinin olduğunu belirtmiştir. Ludwig ve Pittman (1999), yüksek 
öz-yeterliği olan ergenlerin daha az madde kullanımı, antisosyal davranışlar gibi problem davranışlara yöneldiklerini rapor etmiştir. İstismar ve ihmal yaşantısı olan ergenler ile olmayanların karşılaştıııldığı bir çalışmada, özyeterliğin istismar ve davranış sorunları arasindaki ilişkide koruyucu bir faktör olduğu belirtilmiştir (Kim ve Cicchetti, 2003). Sonuç olarak problem davranışlarla ilişkisi dikkate alındığında, duygusal istismar ve problem davranışlar arasındaki ilişkide öz-yeterliğin aracı rolünün olabileceği söylenebilir.

Yukarıda sunulan kuramsal açıklamalar ve ampirik bulgular ışı̆̆ında, duygusal istismara maruz kalan bireylerin daha fazla problem davranışlara yöneldikleri görülmektedir. Dolayısıyla bireyin olumsuz yaşantılar sonrası uyum sağlama becerisinin veya kapasitesi, gerekli eylemlerde bulunma ve organize etmeye yönelik becerisinin, duygusal istismar sonrasında onun psikolojik iyi oluşunu sürdürebilmesinde önemli bir yer edindiği ve problem davranışlara karşı onu koruduğu söylenebilir.
$\mathrm{Bu}$ açıklamalar ışığında, anne-babadan algılanan duygusal istismar, psikolojik sağlamlık, özyeterlik ve problem davranışlar arasındaki ilişki yapısal eşitlik modeli çerçevesinde incelemek, bu çalışmanın temel amacını oluşturmaktadır. Bütün değişkenler arasındaki doğrudan ve dolaylı ilişkilerin tek bir model üzerinde test edilmesi bu amaca hizmet edecektir. Kapsamlı gelişimsel rehberlik hizmetleri çerçevesinde düşünüldüğünde, bu çalışmada elde edilecek bulguların, duygusal istismarın bireyin iyi oluşu üzerindeki etkisini azaltmaya yönelik olarak düzenlenecek önleyici programlar ve müdahale programları için önemli bir temel teşkil edeceğ söylenebilir. Sonuç olarak yukarıdaki kuramsal açıklamalara ve araştırma bulgularına bağlı olarak, "Anne- babadan alg1lanan duygusal istismar ile problem davranışlar ilişkisinde öz-yeterlik ve psikolojik sağlamlık aracılık rolü üstlenecektir" araştırma hipotezi olarak ileri sürülmüştür. Değişkenler arasında kavramsal ilişkiler ve bu ilişkilerin yönünü gösteren model aşağıda yer almaktadır (Şekil1).

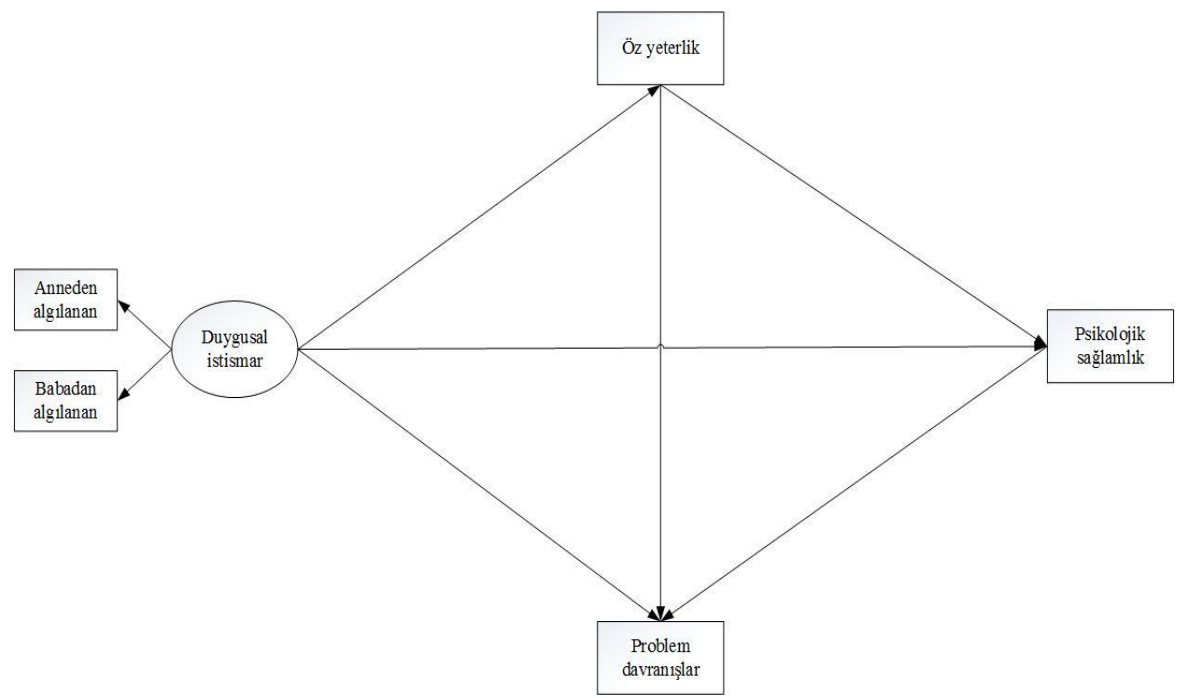

Şekil 1. Değişkenler arasındaki ilişkileri gösteren hipotetik model

2. YÖNTEM

\section{1 Çalışma Grubu}

Çalışmaya Isparta il merkezinde 2014-2015 eğitim öğretim döneminde farklı ortaöğretim kurumlarına devam eden 331 ergen katılmıştır. 
Öğrencilerin \%55.6's1 (184) kız, \%44.1'i (146) erkek katılımcılardan oluşmaktadır. Bir öğrenci ise cinsiyetini belirtmemiştir. Öğrencilerin yaşları 14 ile 19 arasında değişmektedir. Yaş ortalaması 15.43 ve standart sapma $1.17^{\prime}$ dir.

\subsection{Veri Toplama Araçları}

Çocuk ve Genç Psikolojik Să̆lamlık Ölçeği (ÇGPSÖ-12): Ergenlerde psikolojik sağlamlığı ölçme amaciyla Çocuk ve Genç Psikolojik Sağlamıı Ölçeği (ÇGPSÖ-12) kullanılmıştır. Ölçeğin 28 maddelik orijinal formu üç alt ölçek ve sekiz alt boyuttan oluşmaktadır (Liebenberg, Ungar ve Van de Vijver, 2012). Kısa form çalışması Liebenberg, Ungar ve LeBlanc (2013) tarafından yapılmış ve iki farklı çalışma sonucunda 12 maddelik bir yapı elde edilmiştir ("Kendimi okuluma ait hissediyorum", "Ailem zor zamanlarımda yanımdadır"). Uyarlama çalışması Arslan (2015) tarafından yapılmıştır. Ölçeğin madde faktör yüklerinin .54 ile .81 arasında değiştiği ve 12 maddenin toplam varyansın \%51.28'inin tek faktör tarafından açıklandığ görülmüştür. Ölçüt geçerliliği kapsamında olumlu olumsuz duygular ve öz-yeterlikle ilişkisine bakılmış, ÇGPSÖ ile öz-yeterlik ve olumlu duygular arasinda pozitif, olumsuz duygular ile negatif yönde ve anlamlı düzeyde bir ilişkinin olduğu görülmüştür. İç tutarlık katsayısı 91 olarak bulunmuştur. Doğrulayıcı faktör analizi sonuçları ölçeğin iyi düzeyde uyuma sahip olduğunu göstermiştir. Bu çalışmada ölçeğin iç tutarlık katsayısı .90 olarak hesaplanmıştır.

Riskli Davranışlar Ölçeği: Problem davranışları değerlendirmede, Gençtanırım-Kuru (2010) tarafından ergenlik döneminde problem davranışları belirlemek amacıyla geliştirilen Riskli Davranışlar Ölçeği (RDÖ) kullanılmıştır. Ölçek beş alt boyut ve 36 maddeden oluşmaktadır ("Sorunlarım karşısında kendimi çaresiz hissediyorum", "Hakkımı kavga ederek savunurum", "Arkadaşlarımla tartıştı̆̆ımda ă̆zıma geleni söylerim",
"Karamsar biriyim"). Ölçekten yüksek puan almak riskli davranışların yoğunluğuna işaret ederken düşük puan almak ise riskli davranışların düşük düzeyde olduğuna işaret etmektedir. Ölçeğe ilişkin yapılan birinci çalışmada, RDÖ'nün toplamı için iç tutarlık katsayısı .91 ve diğer çalışmada .90 ve test tekrar test çalışması, .85 olarak hesaplamıştır. Bu örneklemde güvenirlik katsayısı .89 olarak bulunmuştur.

Öz-yeterlik Ölçeği: Katılımcıların öz-yeterliği değerlendirmek amacıyla Öz-yeterlik Ölçeği kullanılmıştır. Kısa form çalışması Arslan ve Telef (2015) tarafından yapılan ölçek, dokuz madde ve üç alt ölçekten oluşmaktadır ("Kendinizi iyi hissetmediğinizde kendi kendinize moral vermede ne kadar iyisiniz?", "Olumsuz bir olay karşısında kendi kendinize moralinizi yükseltmeyi ne kadar iyi başarabiliyorsunuz?"). Çalışma sonucunda boyutlara ilişkin iç tutarlık değerlerinin .71 ve .75 arasında değiştiği, toplam iç tutarlık değerinin .84 olduğu görülmüştür. Ölçüt geçerliliği için olumsuz benlik ve psikolojik sağlamlık kullanılmıştır. Öz-yeterliğin olumsuz benlikle negatif, psikolojik sağlamlık ile pozitif yönde ilişki olduğu görülmüştür. Açımlayıcı faktör analiz sonrasında elde edilen üç boyutlu modelin doğrulayıcı faktör analizi sonrasında iyi düzeyde uyum değerleri ürettiğini bulunmuştur. Bu örneklemde iç tutarlık katsayısı $.81^{\prime}$ dir.

Anne-Babadan Algzlanan Duygusal İstismar Ölçe$\breve{g} i$ : Anne-babadan algilanan duygusal istismar, Anne-babadan Algılanan Duygusal İstismar Ölçeği aracılığı ile değerlendirilmiştir (Alantar, 1989; Erkman ve Görkem, 2012; Vardar, 1994) Ölçeğin 32 maddelik kısa form çalışması Arslan ve Kabasakal (2014) tarafından yapılmıştır ("Aile dışında kimselerle beraber olmamı istemez/istemezdi", "Başarısızlıklarımda bana kardeş velveya arkadaşlarımı örnek göstererek eleştirirleleştirirdi”, “Onun koyduğu kuralları çiğnediğim zaman nankör olduğumu söyler /söylerdi"). 
Anne ve baba formu, anne ve babadan algilanan duygusal istismarı değerlendiren ortak maddelerden oluşmaktadır. Ölçeğin iç tutarlık katsayısı anne formu için .88 ve baba formu için .92 bulunmuştur. Doğrulayıcı faktör analizi sonuçları ölçeğin anne-baba formunun iyi düzeyde uyuma sahip olduğu görülmüştür. Bu çalışmada iç tutarlık katsayısı anne formu için .90 ve baba formu için .92 olarak hesaplanmıştir.

\subsection{Verilerin Analiz Süreci}

Uygulama öncesi katılımcılara araştırmanın amacı ve ölçme araçları hakkında kısaca bilgi verilmiştir. Veri toplama araçları gönüllü olan katılımcılara uygulanmıştır. Elde edilen veriler bilgisayar ortamına aktarıldıktan sonra, yapılacak analizler için gerekli varsayımlara bakılmıştır. Öncelikle hatalı ve kayıp veriler frekans dağılımları yardımı ile incelenmiş, hatalı verilere ilişkin gerekli düzeltmeler yapılmıştır. Yapısal modele ilişkin sonuçlar, Ki-kare $\left(\chi^{2}\right), \quad \chi^{2} / \mathrm{sd}$ oranı, iyilik uyum indeksi (GFI), normlaştırılmış uyum indeksi (NFI), karşılaştırmalı uyum indeksi (CFI), standardize edilmiş artık ortala- maların karekökü ( SRMR), fazlalık uyum indeksi (IFI), göreli uyum indeksi (RFI) ve yaklaşık hataların ortalama karekökü (RMSEA) uyum indeksi çerçevesinde değerlendirilmiştir. Veri analizleri SPSS 22 ve AMOS 22 programları aracılığıyla, .05 anlamlılık düzeyiyle test edilmiştir.

\section{BULGULAR}

Betimleyici istatistiklere ilişkin analizlere geçilmeden önce değişkenlere ilişkin basıklık ve çarpıklık değerlerine bakılmıştır. Değişkenlere ilişkin basıklık değerlerinin -.341 ile 1.24 arasında, çarpıklık değerlerinin -.938 ile .964 arasında değiştiği görülmüşsür. Elde edilen basıklık ve çarpıklık değerlerinin normallik varsayımını (Morgan, Leech, Gloeckner ve Barrett, 2004) karşıladığ1 söylenebilir. Değişkenlere ilişkin ortalama ve standart sapma puanları ile değişkenler arasındaki korelasyon değerleri Tablo 1'de gösterilmiştir.

Tablo 1. Değişkenlere İlişkin Ortalama, Standart Sapma ve Korelasyon Değerleri

\begin{tabular}{lccccc}
\hline & 1 & 2 & 3 & 4 & 5 \\
\hline 1. Psikolojik să̆lamlık & 1 & $.452^{* *}$ & $-.395^{* *}$ & $-.313^{* *}$ & $-.315^{* *}$ \\
2. Öz-yeterlik & & 1 & $-.344^{* *}$ & $-.237^{* *}$ & $-.241^{* *}$ \\
3. Anne algilanan duygusal istismar & & & 1 & $.435^{* *}$ & $.398^{* *}$ \\
4. Baba algilanan duygusal istismar & & & & 1 & $.789^{* *}$ \\
5 Problem davranişlar & & & & & 1 \\
Ortalama & 46.11 & 68.56 & 59.80 & 60.49 & 53.81 \\
Standart sapma & 9.719 & 14.86 & 17.50 & 17.65 & 18.25 \\
\hline
\end{tabular}

Not $=N=331,{ }^{* *} p<.001$.

Çalışma kapsamında ele alınan değişkenler arasındaki doğrudan ve dolaylı etkiler, yapısal eşitlilik modeli (YEM) aracılı̆̆ı ile sınanmıştır. Gizil değişkenleri belirlemek amacıyla, anne ve babadan algilanan duygusal istismar formlarından elde edilen değerler duygusal istismar değişkenini tanımlamak için kullanılmıştır. Diğer değişkenler modele gözlenen değişken olarak dâhil edilmiştir. Modele ilişkin uyum değerleri Tablo 2' de verilmiştir.

Analiz sonuçları, anne-babadan algılanan duygusal istismar ile problem davranışlar arasında pozitif yönde ve anlamlı düzeyde bir ilişkinin olduğunu göstermektedir. Ayrıca psikolojik sağlamlık ve öz-yeterlik ile problem davranışlar arasında negatif yönde ve anlamlı düzeyde 
bir ilişki bulunmuştur. Son olarak ise annebabadan algilanan duygusal istismar ile psiko- lojik sağlamlık ve öz-yeterlik arasında negatif yönde bir ilişkinin olduğu görülmektedir.

Tablo 2. Yapısal modele ilişkin uyum değerleri ve uyum kriterleri

\begin{tabular}{lcc}
\hline Uyum & Uyum değeri & Kriter (Kline, 2011; Simşek, 2007) \\
\hline$\chi^{2} /$ sd & 1.68 & $.03^{\prime}$ ten küçük \\
RMSEA & .046 & $.05^{\prime}$ ten küçük \\
GFI & .99 & $.95^{\prime}$ ten büyük \\
NFI & .99 & $.95^{\prime}$ ten büyük \\
RFI & .96 & $.95^{\prime}$ ten büyük \\
CFI & .99 & $.95^{\prime}$ ten büyük \\
SRMR & .011 & $.05^{\prime}$ ten küçük \\
IFI & .99 & .95 'ten büyük \\
\hline
\end{tabular}

Not: $\chi^{2}=3.369, s d=2, p=.186$.

Yapısal eşitlik modeline (YEM) ilişkin analiz sonuçları, modeli destekler niteliktedir. Tablo 2'de verilen analiz sonuçları, önerilen yapısal modelin iyi düzeyde uyum değerleri ürettiğini göstermektedir. Yapısal eşitliğe ilişkin standardize edilmiş parametre değerleri Şekil 2'de verilmiştir.

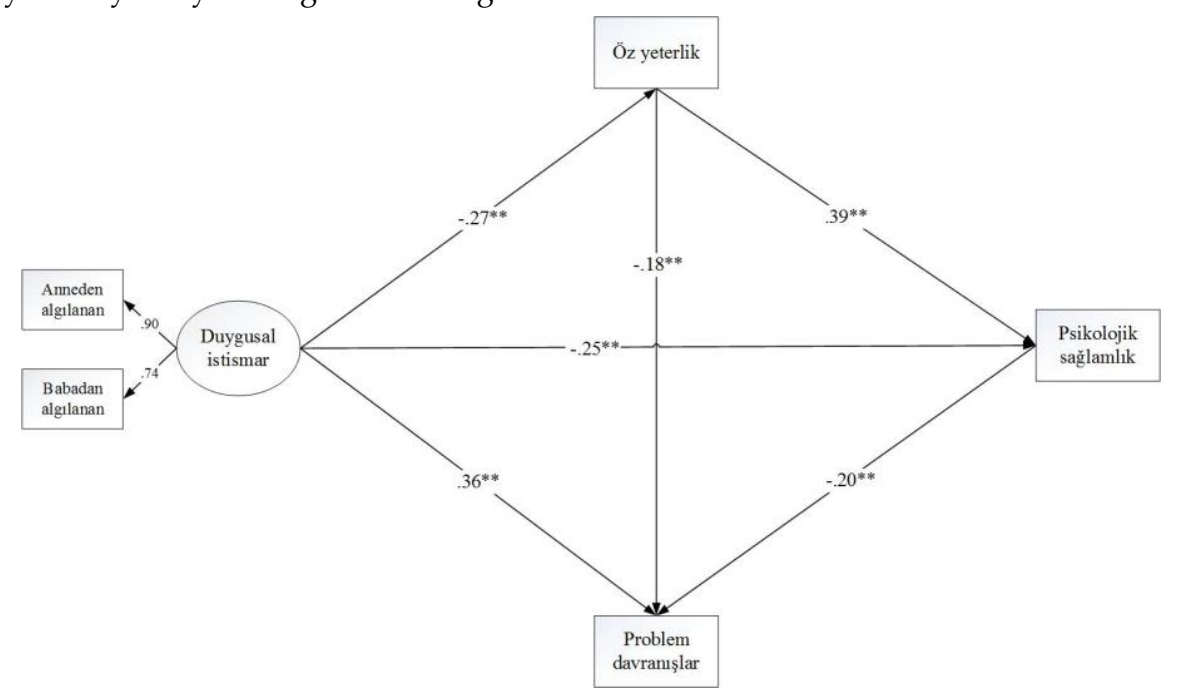

Şekil 2. Yapısal modele ilişkin standardize edilmiş parametre değerler Not: $N=331,{ }^{* *} p<.001$

YEM analiz sonuçları, anne-babadan algılanan duygusal istismarın psikolojik sağlamlığı $(\beta=$ $.25, p<.001)$ ve öz-yeterliği $(\beta=-.27, p<.001) \mathrm{dog}$ rudan yordadığını göstermiştir. Analiz sonuçları, anne-babadan algılanan duygusal istismarın problem davranışları $(\beta=.36, p<.001)$ hem doğrudan hem de öz-yeterlik ve psikolojik sağlamlık aracılığıyla dolaylı olarak yordadığını göstermektedir. Son olarak analizler, psikolojik sağlamlık ( $\beta=-.20, p<.001)$ ve öz-yeterliğin $(\beta=-.18, p<.001)$ problem davranışları, öz- yeterliğin psikolojik sağlamlığı $(\beta=.39, p<.001)$ doğrudan yordadığını göstermektedir. Diğer bir ifadeyle, bulgular anne-babadan algilanan duygusal istismar ve problem davranışlar arasındaki ilişkide psikolojik sağlamlık ve özyeterliğın; duygusal istismar ve psikolojik sağlamlık arasındaki ilişkide öz-yeterliğin kısmi aracı role sahip olduğunu göstermiştir. Anne-babadan algilanan duygusal istismar psikolojik sağlamlığa ilişkin toplam varyansın $\% 12$ 'nin, öz-yeterliğe ilişkin toplam varyansın 
$\% 7^{\prime}$ sini ve son olarak anne-babadan algilanan duygusal istismar, öz-yeterlik ve psikolojik sağlamlığın problem davranışlara ilişkin varyansın \%30’unu açıkladığı görülmüştür.

\section{SONUÇ VE TARTIŞTMA}

Bu çalışmanın amacı, alanyazındaki kuramsal açıklamalar ve araştırma bulgularından yola çıkarak, anne-babadan algılanan duygusal istismar ve problem davranışlar arasındaki ilişkide öz-yeterlik ve psikolojik sağlamlığın koruyucu rolünü incelemektir. Bu amaçla, değişkenler arasındaki ilişkide doğrudan ve dolaylı roller yapısal eşitlik modeli aracılığıyla sınanmıştır. Analiz sonuçları, anne-babadan algilanan duygusal istismarın problem davranışları doğrudan yordadığınınü göstermiştir. $\mathrm{Bu}$ bulgu, duygusal istismara maruz daha fazla problem davranışlar sergiledikleri (Arslan, 2012; Bal, 2010; Ziaian, Anstiss, Antoniou, Baghurst ve Sawyer, 2012) şeklindeki araştırma bulgularıyla tutarlık göstermektedir. Arslan ve Balkıs (2014) istismar ve ihmal ile ergenlikte görülen problem davranışlar arasında pozitif bir ilişkinin olduğunu belirtmişlerdir. Diğer bir çalışmada Bal (2010) çocukluk örselenme yaşantıları (fiziksel, duygusal, cinsel ve istismar yaşantısı toplam) olan öğrencilerin, olmayanlara göre daha fazla kuraldışı davranışlara yöneldiklerini belirtmiştir. Bu bağlamda çocuğa yönelik duygusal istismara neden olabilecek anne-baba yaklaşımlarının, çocuklarda duygusal zarara neden olduğu ve çocuğun psikolojik iyiliğine zarar verdiği söylenebilir (Iwaniec, 2006). Bu bulgular doğrultusunda genel bir değerlendirme yapılacak olursa, ergenlikte duygusal istismara maruz kalan bireylerin daha fazla problem davranışlara yöneldikleri bu çalışmanın sonuçları ile tutarlı olarak söylenebilir.

$\mathrm{Bu}$ araştırmada anne-babadan algılanan duygusal istismar, psikolojik sağlamlık ve özyeterlik arasındaki ilişkiyle tutarlı olarak yapı- lan çalışmalarda duygusal istismar ile psikolojik sağlamlık (Hussain ve Munaf, 2012; Cicchetti, 2013) ve öz-yeterlik (Hussain ve Munaf, 2012; Iwaniec, 2006; Yates, 2007) arasinda negatif bir ilişkinin olduğu rapor edilmiştir. Arslan ve Kabasakal (2014a) tarafından ergenlik döneminde anne-babadan algilanan duygusal istismar arttıkça psikolojik sağlamlığın düştüğü belirtilmiştir. Benzer şekilde öz-yeterliğe ilişkin çalışmalar, istismar yaşantısı olan bireylerin özyeterliklerinin daha düşük olduğunu destekler niteliktedir. Kim ve Cicchetti (2003) tarafından yapılan bir çalışmada istismar ve ihmal yaşantısı olan ergenlerin olmayanlara göre özyeterlik düzeylerinin daha düşük olduğu görülmüştür. Ayrıca çocukluk dönemi istismar yaşantılarının sonraki gelişim dönemlerinde öz-yeterlik üzerinde olumsuz etki bıraktığ1 belirtilmiştir (Singer, Humphreys ve Lee, 2012). Sonuç olarak öz-yeterlik ve psikolojik sağlamlık gelişiminde anne-babadan algılanan duygusal istismarın önemli bir risk faktörlü olduğu söylenebilir.

Araştırma bulguları, psikolojik sağlamlığın, anne-babadan algilanan duygusal istismar ve problem davranışlar ilişkisinde aracılık rolünü üstlendiğini göstermektedir. Diğer bir anlatımla, anne-babadan algilanan duygusal istismarın ve problem davranışlar üzerindeki etkisi bireylerin psikolojik sağlamlık düzeyine bağlı olarak değişebilmektedir. Anne-babadan algilanan duygusal istismar arttıkça ergenlerde psikolojik sağlamlık düşülmekte ve bununla birlikte problem davranışlarda artış yaşanmaktadır (Kabasakal ve Arslan, 2014). Bu bulgu psikolojik sağlamlığın koruyucu rolüne vurgu yapan çalışmalarla tutarlık göstermektedir (Benetti ve Kambouropoulos, 2006; Kabasakal ve Arslan, 2014). Çataloğlu (2011) tarafından psikolojik sağlamlık düzeyi yüksek olan ergenlerin, psikolojik sağlamlığı düşük olan akranlarına oranla madde kullanımının daha düşük olduğunu belirtmiştir. Gardner, Dishion ve Connell (2008) 
psikolojik sağlamlık düzeyi yüksek olan ergenlerin akranları tarafindan olumsuz davranışlara maruz bırakıldıklarında daha düşük düzeyde anti-sosyal davranışlar gösterdiklerin belirtilmiştir. Ziaian ve arkadaşları (2012) duygusal ve davranışsal problemlere sahip olan bireylerin psikolojik sağlamlıklarının daha düşük olduğunu rapor etmiştir. Benzer şekilde, Lee ve Cranford (2008) düşük psikolojik sağlamlığa sahip bireylerin daha fazla uyum sorunları yaşadıklarını, problem davranışlara yöneldiklerini belirtmiştir.

Diğer önemli bir bulgu ise anne-babadan alg1lanan duygusal istismar-problem davranışlar ve duygusal istismar-psikolojik sağlamlık arasındaki ilişkide öz-yeterliğin aracı rolüne ilişkindir. Daha önce yapılan çalışmalar ile tutarlı olarak (Bandura ve diğerleri, 1999; Hussain ve Munaf, 2012; Iwaniec, 2006; Kim ve Cicchetti, 2003; Uysal ve Yllmaz-Bingöl, 2014), yüksek öz-yeterliğin problem davranışlara karşı koruyucu bir faktör olduğu bulunmuştur. Öz-yeterlik bireyin duygu, düşünce ve davranışlarını şekillendiren önemli bir faktörlerden biridir. Öz-yeterlik bireyin duygu, düşünce ve davranışları üzerindeki etkisiyle, dolaylı olarak ergeni problem davranışlara karşı koruyabilmektedir. Güçlü öz-yeterlik inanc1, olumsuz yaşantılar ile başa çıkmayı kolaylaştırır (Bandura, 1994) ve problem davranışlara karşı koruyucu bir rol üstlenir. Bandura, Pastorelli, Barbaranelli ve Caprara (1999) tarafından akademik öz-yeterliğin problem davranışları anlamlı düzeyde yordadığını ve problem davranışlar üzerinde önemli rol oynadığı belirtilmiştir. Ayrıca öz-yeterlik inancı, olumsuz bir yaşantı ile karşılaştığında, normlar çerçevesinde davranışlarını düzenlemede bireye yardımcı olur (Caprara, Barbaranelli, Pastorelli ve Cervone, 2004). Olumsuz yaşam olayları veya risk durumları karşısında, bireyin yüksek özyeterlik duygusuna sahip olması, bu yaşantıları nasıl yöneteceği belirler ve problem davranışla- ra karşı bireyi korur (Telef ve Karaca, 2011). Örneğin Kim ve Cicchetti (2003) istismar ve ihmal yaşantısı olan ergenler ile olmayanları karşılaştırmış ve öz-yeterliğin istismar ve problem davranışlar arasındaki ilişkide koruyucu bir faktör olduğunu bulmuştur. Sonuç olarak ergenlikte anne-babadan algilanan duygusal istismara karşı öz-yeterlik ve psikolojik sağlamlık düzeyinin yüksek olmasının bireyi problem davranışlara karşı koruduğu söylenebilir.

$\mathrm{Bu}$ çalışmanın bulguları, anne-babadan algılanan duygusal istismarın düzeyi artıkça bireyin daha fazla problem davranışa yöneldiğini göstermiştir. Ayrıca bulgular incelendiğinde, duygusal istismara maruz kalan bireylerin psikolojik sağlamlık ve öz-yeterlik düzeyi yüksek olduğunda duygusal istismar sonrasında daha az problem davranışlara yöneldikleri görülmektedir. Buradan hareketle okul psikolojik danışmanları tarafından, uyum sorunu yaşayan ergenlere yönelik psiko-eğitim programlar aracılığıyla öğrencilerin öz-yeterlik inançlarını ve psikolojik sağlamlığı destekleyici çalışmalar yürütülebilir. Yapılacak bu çalışmaların olumsuz yaşantılara sahip öğrencilerde görülebilecek uyum sorunları üzerinde koruyucu role sahip olacağı söylenebilir. Ayrıca anne-babadan algilanan duygusal istismarın problem davranışlar üzerindeki doğrudan etkisi dikkate alındığın, duygusal istismar konusunda ebeveynlere, öğretmenlere ve okul yöneticilerine yönelik bilgilendirme çalışmaları yürütülebilir. Psikolojik danışmanlar tarafından, eğitim öğretim sürecinde duygusal istismara uğrayan bireylerin belirlenmesi, bu öğrencilere yönelik grupla psikolojik danışma ve bireyle psikolojik danışma çalışmalarının yürütülmesinin, duygusal istismarın problem davranışlar üzerindeki olumsuz etkilerini azaltmada katkı sağlayacağı söylenebilir. Son olarak olumsuz yaşantılara sahip ve uyum sorunları yaşayan öğrencilere yönelik öz-yeterliği ve psikolojik sağlamlığı destekleyici grupla psiko- 
lojik danışman çalışmalarının yürütülmesi, problem davranışlara yönelik koruyucu işlev göreceği söylenebilir.

$\mathrm{Bu}$ çalışmada elde edilen sonuçlar birtakım sınırlılıklar içeresinde değerlendirilebilir. Birincisi, araştırmamız nicel verilere dayalı bir çalışmadır. Bu nedenle gelecek araştırmalarda değişkenler arası ilişkilerle ilgili daha detaylı bir resmin elde edilmesi bakımından, nitel çalışma ya da nitel ve nicel yöntemlerin birlikte kullanıldığı karma desen çalışmaları yapılabi- lir. İkincisi, modelin farklı olumsuz yaşantılara sahip olan gruplarda sinamaya yönelik benzer çalışmalar yapılabilir. Üçüncüsü, bu çalışmada aracı değişkenler olarak öz-yeterlik ve psikolojik sağlamlık alınmıştır. Gelecekte farklı değişkenlerin aracı rolüne ilişkin yeni çalışmalar yapılabilir. Son olarak bu çalışmanın kesitsel olması bir sınırlılık olarak düşünülebilir. Boylamsal araştırmaların yapılmasının faydalı olacağı düşünülmektedir.

\section{Kaynakça}

Alantar, M. (1989). Psychological Maltreatment: An Attempt of İts Definition by Experts and Its Assessment Among a Group of Adolescents, Unpublished Master Thesis, Bogaziçi University.

Arslan, G. ve Telef, B. B. (2015). Öz-Yeterlik Ölçeği: Ergenler İçin Kısa Form Çalışması. 24. Ulusal Eğitim Bilimleri Kongresi, 16-18 Nisan, Niğde.

Arslan, G. (2012). Ortaöğretimde Öğrenim Gören Ergenlerde Görülen Problem Davranışların Aile Sorunları, Aile Yapısı Açısından Incelenmesi. Yayınlanmamış Yüksek Lisans Tezi, Sosyal Bilimler Enstitüsü, Pamukkale Üniversitesi, Denizli.

Arslan, G. (2015). Çocuk ve Genç Psikolojik Sağlamlık Ölçeği: Geçerlik ve Güvenirlik Çalışması, Ege Eğitim Dergisi, 2015 (16) 1: 1-12.

Arslan, G. ve Balkis, M. (2014). Ergenlikte Görülen Problem Davranışlar ve Aile Sorunları Arasındaki İlişkilerin İncelenmesi. Süleyman Demirel Üniversitesi Uluslararası Eğitim Çalışmaları Dergisi, 1(1), 11-23.

Arslan, G. ve Kabasakal, Z. (2014a). Ergenlikte Algılanan Duygusal İstismar ve Psikolojik Sağlamlık Arasındaki İlişki, VI International Congress of Educational Research, Hacettepe University: Ankara.

Bal, S. (2010). Çocukluk Örselenme Yaşantıları, Ana-Baba-Ergen İlişki Biçimleri, Sosyal Destek Algısının, Kural Dışı Davranışlarla İlişkisi, Yayınlanmamış Yüksek Lisans Tezi, Çukurova Üniversitesi, Adana.

Bandura, A. (1994). Self-Efficacy. In V. S. Ramachaudran (Ed.), Encyclopedia of human behavior (Vol. 4, pp. 71-81). New York: Academic Press.

Bandura, A. (1997). Self-Efficacy: The Exercise of Control. New York: Freeman.

Bandura, A., Pastorelli, C., Barbaranelli, C. ve Caprara, G. V. (1999). Self-Efficacy Pathways to Childhood Depression. Journal of Personality and Social Psychology, 76(2), 258-269.

Benetti, C. ve Kambouropoulos, N. (2006). Affect-Regulated Indirect Effects of Trait Anxiety and Trait Resilience on Self-Esteem. Personality and Individual Differences, 41, 341-352.

Bolger, K. E. ve Patterson, C. J. (2003). Sequelae of Child Maltreatment: Vulnerability ad Resilience. S. S. Luthar (Ed.), Resilience and Vulnerability: Adaptation in The Context of Childhood Adversities (pp. 156-181). New York: Cambridge University Press.

Caprara, G. V., Barbaranelli, C., Pastorelli, C. ve Cervone, D. (2004). The Contribution of Self-Efficacy Beliefs to Psychosocial Outcomes in Adolescence: Predicting Beyond Global Dispositional Tendencies. Personality and individual Differences, 37(4), 751-763. 
Cicchetti, D. (2013). Annual Research Review: Resilient Functioning in Maltreated Children-Past, Present, and Future Perspectives. Journal of Child Psychology and Psychiatry, 54 (4), 402-422.

Çataloğlu, B. (2011). Madde Kullanan ve Kullanmayan Ergenlerin Psikolojik Sağlamlık, Aile İşlevleri Açısından Karşılaştırılması, Yayınlanmamış Yüksek Lisans Tezi, Dokuz Eylül Üniversitesi, İzmir.

DSM-V (2013). Diagnostic and Statistical Manual of Mental Disorders, American Psychiatric Association

Erkman, F. ve Görkem, E. (2012). A Perceived Emotional Maltreatment Inventory: Development of the Short Form (POPMIFA -Short Form). Paper Presented Child Abuse and Neglect Prevention Conference in İstanbul.

Evans, C. B. ve Burton, D. L. (2013). Fi, Types of Child Maltreatment and Subsequent Delinquency: Physical Neglect as the Most Significant Predictor. Journal of Child Adolescent Trauma, 6(4), 231-245.

Fergusson, D.M. ve Horwood, L.J. (2003). Resilience to Childhood Adversity: Results of a 21 Year Study. S.S. Luthar (Ed.), Resilience and Vulnerability: Adaptation in the Context of Childhood Adversities (s.130-155). New York: Cambridge University Press.

Gardner, T. W., Dishion, T. J. ve Connell, A. M. (2008). Adolescent Self-Regulation as Resilience: Resistance to Antisocial Behavior within the Deviant Peer Context. Journal of Abnormal Child Psycho$\log y, 36(2), 273-284$.

Gençtanırım-Kuru (2010). Ergenlerde Riskli Davranışların Yordanması. Yayınlanmamış Doktora Tezi. Hacettepe Üniversitesi, Sosyal Bilimler Enstitüsü.

Gizir, C. A. (2007). Psikolojik Sağlamlık, Risk Faktörleri ve Koruyucu Faktörler Üzerinde Bir Derleme Çalışması. Türk Psikolojik Danışma ve Rehberlik Dergisi, 3(28), 113-128.

Holden, G. W. ve Ritchie, K. L. (1991). Linking Extreme Marital Discord, Child Rearing, and Child Behavior Problems: Evidence from Battered Women. Child delopment, 62(2), 311-327.

Hussain, S. ve Munaf, S. (2012). Perceived Father Acceptance-Rejectıon in Childhood and Psychological Adjustment in Adulthood, International Journal of Business and Social Science, 3, 1.

Ireland, T. O. ve Smith, C. A., Thornberry, T. P. (2002). Developmental issues in the impact of child maltreatment on later delınquency and drug use. Criminology, 40(2), 359-400.

Iwaniec, D. (2006) The Emotionally Abused and Neglected Child: Identification, Assessment and Inter,Ntion A Practice Handbook, JohnWileySon, Ltd, England.

Iwaniec, D., Larkin, E. ve McSherry, D. (2007). Emotionally Harmful Parenting. Child Care in Practice, 13(3), 203-220.

Kabasakal, Z. ve Arslan, G. (2014). Ergenlikte Görülen Anti-Sosyal Davranışlar, Psikolojik Sağlamlık ve Aile Sorunları Arasındaki İlişki, Uluslararası Hakemli Aile Çocuk ve Ĕ̆itim Dergisi, 2 (3), 76-90.

Kim, D. H. ve Im, Y. J. (2014). Resilience as A Protecti, Factor For the Behavioral Problems in schoolAged Children with Atopic Dermatitis. Journal Of Child Health Care, 18(1), 47-56.

Kim, J. ve Cicchetti, D. (2003). Social Self-Efficacy and Behavior Problems in Maltreated and Nonmaltreated Children. Journal of Clinical Child and Adolescent Psychology, 32(1), 106-117.

Klika, J. B. ve Herrenkohl, T. I., Lee, J. O. (2013). School Factors As Moderators of The Relationship Between Physical Child Abuse and Pathways of Antisocial Behavior. Journal of Interpersonal Violence, 28(4), 852-867.

Kline, R. B. (2011). Principles and Practices of Structural Equation Modeling. New York: The Guil-Ford Press. 
Korkmazlar-Oral, Ü., Engin, P. ve Büyükyazıcı, Z. (2010). Türkiye'de Çocuk İstismarı ve Aile İçi Şiddet Araştırması: Özet Raporu. Ankara: T.C. Başbakanlık Sosyal Hizmetler ve Çocuk Esirgeme Kurumu.

Lee, H. H. ve Cranford, J. A. (2008). Does Resilience Moderate the Associations Between Parental Problem Drinking and Adolescents' İnternalizing and Externalizing Behaviors?: A Study of Korean Adolescents. Drug and Alcohol Dependence, 96(3), 213-221.

Liebenberg, L., Ungar, M. ve LeBlanc, J. C. (2013). The CYRM-12: A Brief Measure of Resilience. Canadian Journal of Public Health, 104(2), 131-135.

Liebenberg, L., Ungar, M. ve Van de Vijver, F. R. R. (2012). Validation of The Child and Youth Resilience Measure-28 (cyrm-28) Among Canadian Youth with Complex Needs. Research on social work practice, 22(2), 219-226.

Ludwig, K. B. ve Pittman, J. F. (1999). Adolescent Prosocial Values and Self-Efficacy in Relation to Delinquency, Risky Sexual Behavior, and Drug Use. Youth \& Society, 30(4), 461-482.

Masten A. S. (2001). Resilience Process in Development. American Psychologist, 56 (3), 227-238.

McGee, R. A., Wolfe, D. A. ve Wilson, S. K. (1997). Multiple Maltreatment Experiences and Adolescent Behavior Problems: Adolescents' Perspectives. De,lopment and Psychopathology, 9(01), 131-149.

Morgan, G. A., Leech, N. L. Gloeckner, G. W. ve Barrett, K. C. (2004). SPSS For Introductory Statistics: Use And Interpretation. Psychology Press.

Rew, L. ve Horner, S. D. (2003). Youth Resilience Framework for Reducing Health-Risk Behaviors in Adolescents. Journal of Pediatric Nursing, 18(6), 379-388.

Sameroff, A. (2005). Early Resilience and İts Developmental Consequences. In: Tremblay RE, Barr RG, Peters RDeV, eds. Encyclopedia on Early Childhood Development [online]. Montreal, Quebec: Centre of Excellence for Early Childhood Development; 2005:1-6.

Singer, M., Humphreys, K. ve Lee, S. (2012). Coping Self-Efficacy Mediates the Association Between Child Abuse and ADHD in Adulthood. Journal of Attention Disorders. 1-9. oi:10.1177/1087054712465337

Stewart, M., Reid, G.J. ve Mangham, C. (1997). Fostering Children's Resilience. Journal of Pediatric Nursing, $12(1), 21-31$.

Şimşek, Ö. F. (2007). Yapısal Eşitlik Modellemesine Giriş: Temel Illkeler ve Lisrel Uygulamaları. Ankara: Ekinoks Yayınevi.

Taşdelen, N. (1995). Examination of the Effects of Perceived Psychological Maltreatment of Mothers on Adolescent's Self Concept, Emotional and Behavioral Problemsand Academic Achievement (Unpublished Thesis). Bogaziyi University.

Telef, B. B. ve Karaca, R. (2011). Ergenlerin Öz-Yeterliklerinin ve Psikolojik Semptomlarının İncelenmesi. Mustafa Kemal Üniversitesi Sosyal Bilimler Enstitüsü Dergisi, 8(16), 499-518.

Uysal, R. ve Bingöl, T. Y. (2014). Ergenlerde Risk Alma Davranışının Öz-Yeterlik ve Farklı Değişkenler Açısından İncelenmesi. Akademik Sosyal Araştırmalar Dergisi, 2 (8), 573-582.

Vardar, B. (1994). The Reliability and Validity Study of Perception of Psychological Maltreatment Inntory for Adolescents, Unpublished Master's Thesis, Boğaziçi University

Vranceanu, A. M., Hobfoll, S. E. ve Johnson, R. J. (2007). Child Multi-Type Maltreatment and Associated Depression and PTSD Symptoms: The Role of Social Support and Stress. Child Abuse and Neglect, 31(1), 71-84. 
Windle, M. (2002). Critical Conceptual and Measurement İssues in the Study of Resilience. (Ed: M. D. Glantz , J. L. Johnson) Resilience and DeveLopment: Positive, Life Adaptations. New York: Kluwer Academic/Plenum Publishers.

World Health Organization [WHO]. (1999). Report of the Consultation on Child Abuse Prevention, 29-31 March, Genava.

Yates, T. M. (2007). The Developmental Consequences of Child Emotional Maltreatment: A Neurodevelopmental Perspective. Journal of Emotional Maltreatment, 7 (2), 9-34.

Ziaian, T., Anstiss, H., Antoniou, G., Baghurst, P. ve Sawyer, M. (2012). Resilience and İts Association with Depression, Emotional and Behavioural Problems, and Mental Health Service Utilisation Among Refugee Adolescents Living in South Australia. International Journal of Population Research, 2012. doi:10.1155/2012/485956. 


\section{Extended Summary}

Emotional maltreatment is a crucial problem in Turkey (Korkmazlar-Oral, Engin \& Büyükyazıcl, 2010). Emotional maltreatment is acts of parent or caregiver that result in significant psychological harm to the child (Diagnostic and Statistical Manual of Mental Disorders [DSM-V], 2013; World Health Organization [WHO], 1999). It is also can lead to various externalizing and internalizing problems in adolescent (Bolger \& Patterson, 2003; Iwaniec, 2006; Vranceanu, Hobfoll, \& Johnson, 2007). Studies support that emotional maltreatment perceived from parent can cause various problem behaviors such as alcohol use, antisocial behavior, and suicide in adolescence (Arslan \& Balk1s, 2014; Holden \& Ritchie, 1991; Ireland et al., 2002; Kabasakal \& Arslan, 2014; Taşdelen, 1995). Researchers, for example, that emotional maltreatment is associated with delinquency, antisocial behavior, alcohol use, suicide tendency, tobacco use or smoking, and various nutritional problems in adolescents (Arslan, 2012; Bal, 2010; Evans \& Burton, 2013; Kabasakal \& Arslan, 2014). Research also reported that some personal, family, and social characteristics of individuals can help to cope with risk or adversity successfully, including emotional maltreatment. Psychological resilience and self-efficacy are two important resources in this adaptation process. Research reported that emotional maltreatment is negatively associated with psychological resilience and self-efficacy (Hussain ve Munaf, 2012; Cicchetti, 2013; Iwaniec, 2006; Yates, 2007). For example, Kabasa$\mathrm{kal}$ and Arslan (2014) reported that emotional maltreatment is negatively associated with psychological resilience while positively related to antisocial behavior in adolescents. Cicchetti (2003) found that individual who exposed to abuse experiences have low level of self-efficacy compared to non-abused. Studies also support that individuals with high levels of psychological resilience and self-efficacy can more successfully cope with negative life experiences (Fergusson \& Horwood, 2003; Hussain \& Munaf, 2012; Iwaniec, 2006; Kabasakal \& Arslan, 2014; Kim \& Im, 2014; Kim \& Cicchetti, 2003; Rew \& Horner, 2003). As a result, we can say that psychological resilience and self-efficacy may mediate in relationship between child emotional maltreatment and problem behaviors in adolescents. The purpose of this study is, therefore, to investigate the mediating role of psychological resilience and self-efficacy in relationship between emotional maltreatment and problem behaviors. The direct and indirect relationships among variables are presented in Figure 1 with hypothetical model.

Child and Youth Resilience Measure (Arslan, 2015), Problem Behaviors Scale (Gençtanırım-Kuru, 2010), Self-Efficacy Scale (Arslan \& Telef, 2015), and Emotional maltreatment Perceived from Parents (Arslan \& Kabasakal, 2014) were applied adolescents. The measures were applied 331 students studying different high school in Isparta. Participants consisted of 55.6\% (184) female, $44.1 \%$ (146) male students. The ages of the students ranged between 14 and 19. The mean of ages were 15.43 and standard division was 1.17. For data analysis, SPSS 22 and AMOS 22 program were used. Structural equation analysis was conducted to examine direct and indirect relationships among variables.

Before the data analysis, assumptions of multivariate analysis were checked. Then, descriptive statistics and correlation analysis were examined by using SPSS 22. These results are presented in Table 1 . The results indicated that emotional maltreatment positively correlated with problem behaviors while negatively correlated with psychological resilience and self-efficacy. Structural equation results also showed that emotional maltreatment perceived from parents directly predict problem behaviors, psychological resilience, and self-efficacy. Furthermore, the findings indicated that psychological resilience and selfefficacy partially mediated in relationship between emotional maltreatment and problem behaviors in adolescents. Emotional maltreatment explained of $12 \%$ of variance in psychological resilience and $7 \%$ of 
variance in self-efficacy. Emotional maltreatment, psychological resilience, and self-efficacy, together, accounted for $30 \%$ of variance in problem behaviors.

The aim of present study was to examine the mediating role of psychological resilience and self-efficacy in relationship between emotional maltreatment and problem behaviors in adolescents. Results of analysis indicated that emotional maltreatment perceived parents directly predicted psychological resilience, self-efficacy and problem behaviors. Results also showed that emotional maltreatment perceived parents indirectly predicted problem behaviors via self-efficacy and psychological resilience. In other words, psychological resilience and self-efficacy had partial mediation role in relationship between emotional maltreatment and problem behaviors in adolescents. These results are discussed the role of self-efficacy and psychological resilience as protective factors in the link between emotional maltreatment and problem behaviors, and some suggestions were made. 